\title{
A Review of Predictive Software for the Design of Community Microgrids
}

\author{
Mina Rahimian $\left(\mathbb{D},{ }^{1}\right.$ Lisa D. Iulo, ${ }^{2}$ and Jose M. Pinto Duarte $\mathbb{D}^{3}$ \\ ${ }^{1}$ Stuckeman School of Architecture, The Pennsylvania State University, University Park, PA, USA \\ ${ }^{2}$ Hamer Center for Community Design, Stuckeman School of Architecture, The Pennsylvania State University, \\ University Park, PA, USA \\ ${ }^{3}$ The Stuckeman Center for Design Computing, Stuckeman School of Architecture, The Pennsylvania State University, \\ University Park, PA, USA \\ Correspondence should be addressed to Mina Rahimian; mxr446@psu.edu
}

Received 8 September 2017; Revised 16 December 2017; Accepted 31 December 2017; Published 20 February 2018

Academic Editor: Dan Wang

Copyright (C) 2018 Mina Rahimian et al. This is an open access article distributed under the Creative Commons Attribution License, which permits unrestricted use, distribution, and reproduction in any medium, provided the original work is properly cited.

\begin{abstract}
This paper discusses adding a spatial dimension to the design of community microgrid projects in the interest of expanding the existing discourse related to energy performance optimization measures. A multidimensional vision for designing community microgrids with higher energy performance is considered, leveraging urban form (superstructure) to understand how it impacts the performance of the system's distributed energy resources and loads (infrastructure). This vision engages the design sector in the technical conversation of developing community microgrids, leading to energy efficient designs of microgrid-connected communities well before their construction. A new generation of computational modeling and simulation tools that address this interaction are required. In order to position the research, this paper presents a survey of existing software packages, belonging to two distinct categories of modeling, simulation, and evaluation of community microgrids: the energy infrastructure modeling and the urban superstructure energy modeling. Results of this software survey identify a lack in software tools and simulation packages that simultaneously address the necessary interaction between the superstructure and infrastructure of community microgrids, given the importance of its study. Conclusions represent how a proposed experimental software prototype may fill an existing gap in current related software packages.
\end{abstract}

\section{Introduction}

Energy production is typically a regional enterprise, with the majority of energy produced far from the main areas of demand. This causes tremendous problems in terms of lack of resiliency and flexibility in handling the ever-changing demands at the users' end and the continuous changes of the dynamic environment [1-4]. Microgrids, on the other hand, as localized energy infrastructures, support resiliency in the electrical grid by exercising greater control over the production by generating energy close to its point of consumption. Microgrids integrate various techniques of automation, optimization, pervasive control, and computation on both the supply and demand side [5-7].

The US Department of Energy defines a microgrid as a "group of interconnected loads and distributed energy resources within clearly defined electrical boundaries that acts as a single controllable entity with respect to the grid. A microgrid can connect and disconnect from the grid to enable it to operate in both grid-connected or island-mode" [8]. Microgrids comprise two main components, their subcomponents, and the distribution facilities among them [9-11]:

(i) Distributed energy resources (DER) include the following:

(a) Distributed energy generators include renewable (i.e., solar electric, solar thermal, wind turbine, biomass) and nonrenewable energy resources (i.e., internal combustion engine, fuel cells, combined cycle gas turbine) that produce energy onsite, meeting the microgrid loads' energy demand. 
(b) Energy storage devices include batteries, flywheels, and supercapacitors that take care of balancing onsite energy generation and energy demand in microgrids. Among responsibilities of energy storage devices are responding to power disruptions resulting from intermittent onsite energy generation, providing initial energy for a seamless transition between gridconnected and island mode, and allowing different energy generators to work as dispatchable generation units.

(ii) Loads are the customers that the microgrid local power infrastructure serves. Loads are mainly classified based on the demand of high degree power quality and reliability in the event of an outage [10]. By this, loads are classified into critical loads such as military sites, hospitals, and university campuses where even momentary power interruptions will cause significant financial and physical consequences and noncritical loads such as residential buildings and urban communities.

(iii) Distribution facilities include wires and transformers for delivering electricity and pipes to transmission useful steam and hot or chilled water to the loads within the network.

In this research, the configuration of the electrical components and distribution facilities of a microgrid is referred to as the "microgrid infrastructure" which also outlines the microgrid's electrical boundaries. Different microgrid installations have different electrical configurations which implicate the mix of generators, storages, and loads that they support. These differences depend on various parameters such as resource availability, geographical locations, load demand, and the existing electrical transmission and distribution systems [11].

As stated in the microgrid definition suggested by the US Department of Energy, microgrids are equipped with controlling capabilities that make them technically able to disconnect from the larger power grid by isolating a group of buildings and self-powering them with onsite energy generation technologies. The state of disconnection from the larger power grid is known as "islanding." The process of islanding prepares the microgrid for serving as emergency backup for critical and sensitive loads, providing security, reliability, and resiliency under unexpected environmental conditions of resource depletion or a rise on energy expenses. In addition to critical loads, microgrids are emerging as the local power infrastructure for communities in urban contexts that are not necessarily known as critical loads. According to the New York State Energy Research and Development Authority, which in 2015 financially supported microgrid development in 83 communities in the state of New York [12], the rise of microgrid-connected communities in cities is specifically geared towards reducing energy costs and greenhouse gas emissions as well as developing energy independent urban settlements.

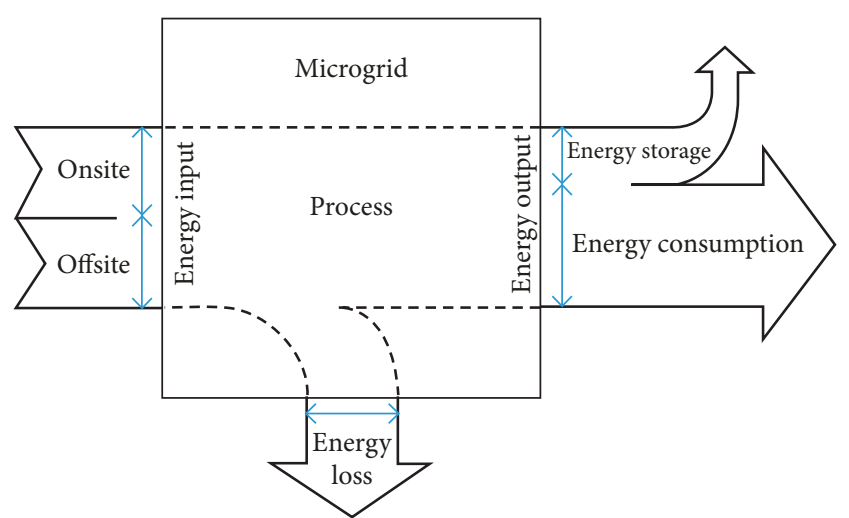

FIGURE 1: Energy performance in a microgrid can be evaluated by comparing the energy input to the energy output.

Community Microgrids' Energy Performance. As in any energy system, the efficiency of a microgrid's energy performance depends on the ratio of energy input to energy output [13]. The energy that is inputted to a microgrid comes from a combination of on- and offsite resources, and the energy output is the useful energy utilized for the operation of buildings and any mechanical system that is tied to the microgrid infrastructure, as well as the excess energy that gets stored in a microgrid's designated storage devices. In addition to the outputted useful energy, in the conversion process from energy input to energy output, a portion of energy gets wasted mostly in form of heat (Figure 1).

According to Figure 1 and the definition above, improving a microgrid's energy performance involves maximizing energy input (particularly the energy that is generated via onsite renewables), minimizing energy loss (when analyzing energy performance in a community microgrid, due to the scale of study, the amount of energy loss can be neglected since it is very minimal; therefore, energy performance in this research does not include energy loss), minimizing energy consumption, and maximizing stored energy (which could be either used by the loads when needed or sold back to the larger grid). Wouters [14] explains that with the purpose of improving a microgrid's energy performance most research to date has focused on overcoming the technical issues and operational efficiency of each individual generation, distribution, storage, and consumption technologies.

This paper discusses energy performance in community microgrids in the interest of expanding the existing discourse by adding a spatial dimension to its definition. The contention of this research is that a community microgrid's energy performance goes beyond overcoming the operational efficiency of each individual component of its infrastructure, arguing that there is a relationship between the urban form of the buildings in a community and how well the microgrid's infrastructure performs in terms of supply and demand of energy. The validity of this argument is demonstrated by the fact that community microgrids are contextualized in urban areas and cities. Numerous studies from the 1970s to date have discussed the impact that the spatial structure of urban form has on buildings' energy requirements for space 
heating and cooling, as well as the feasibility of adopting energy conservative technologies such as onsite renewable energy generators as solar and wind (this concept will be fully discussed in the Vision and State of the Art). The spatial structure of urban form in this context is not limited to buildings but also contains the urban spaces among the buildings and how the relationship among them is defined. To better understand the energy performance of a community microgrid, there is a need to explore the impact that the urban form of a microgrid-connected community has on the amount of renewable energy that is captured onsite as part of the inputted energy and the amount of energy that is required for buildings' major operations including space heating and cooling (Owens [15] argues that the major source of energy consumption in buildings is for space heating and cooling) (the useful energy outputted).

\section{Vision and State of the Art}

A study of community microgrids in isolation from their comprising buildings is insufficient and limits a holistic understanding of community microgrids as buildingintegrated energy systems. Generally speaking, community microgrids are constituted by two main components: (1) the infrastructure, which is the combination of electrical components and distribution facilities, and (2) superstructure, which consists of the interconnected buildings that are tied together via the microgrid's infrastructure and the urban spaces in between them. There are direct relationships between buildings in a community and the microgrid infrastructure that inform energy performance. While the DOE definition of microgrids emphasizes "clearly defined electrical boundaries" [8], a spatial recognition of community microgrids must also include clearly defined regional boundaries informed by the microgrid's interconnected buildings.

In order to offer a comprehensive understanding of a community microgrid's energy performance, a model that describes the relationship between the spatial configuration of urban form and the energy performance of its underlying infrastructure needs to be considered. Towards this end, the following review is intended to outline how different spatial attributes of urban form impact the amount of renewable energy captured onsite and the amount of energy consumed by buildings within a community.

\subsection{Urban Form and Energy Performance in Community} Microgrids. Literature verifies the need for a multidimensional vision on community microgrids relating the spatial structure of urban form to energy performance in different urban contexts. Some sources assess the feasibility of utilizing renewable energy supply and distribution systems (Lund, 2009) and the amount of energy demanded in buildings particularly for space heating, cooling, and lighting [15-17]. For example, a decentralized shared energy system with a complementary mix of land uses is suggested to be more economically beneficial due to balancing the peak hour of energy consumption [18] and it is suggested that communities with higher densities facilitate the introduction of CHP systems in particular contexts [15].
Solar energy is one of the main sources of renewable energy available. Therefore, studies considered herein explore the relationships between aggregated attributes of urban form and the potential to harvest solar energy within the urban context and communities to generate photovoltaic energy. For example, a study by Sarralde et al. (2014) on different neighborhoods in London shows how optimizing a combination of nine spatial attributes of urban form (including share of semidetached houses, average building height, share of area covered by private gardens, site coverage, average building perimeter, average distance between buildings, standard deviation of building heights, plot ratio, and average distance between buildings) could increase the solar irradiation of roofs by $9 \%$ and facades by $45 \%$. A research by Robinson (2006) examines the effect of urban morphology and indicators of radiation availability including the sky view factor, mean canyon height to width ratio, and the urban horizon angle of three Swiss districts. Compagnon [19] looks at how the orientation of 61 buildings in a certain area of Fribourg impacts the potential of capturing solar energy by the building facades and roofs. Moreover, a paper by Lobaccaro and Frontini [20] examines building densification and shading in urban environments as two effecting factors for solar availability and potential for utilizing photovoltaic panels in certain communities and neighborhoods.

According to Contribution of Working Group III to the Fifth Assessment Report of the Intergovernmental Panel on Climate Change [21], urbanization is ranked as the fifth contributor (this report ranks economic geography and income, sociodemographic factors, technology, and infrastructure as first four contributors to greenhouse gas emissions in urban areas) to greenhouse gas emissions in urban areas. With the growing rate of urbanization, significant changes in land use pattern and urban form have emerged [22]. Numerous studies have proven different ways of understanding how urbanization drives energy consumption as a consequence of economic development and growth in the income rate [2326]. The association between urban form and greenhouse gas emissions is largely due to the impact that the spatial configuration of urban form has on patterns of mobility in cities and the energy required for space heating and cooling in individual buildings [15].

Newman and Kenworthy [27] assert that research on urban form and energy demand for traveling purposes in cities has been investigated throughout the years. However, not much literature to date has been dedicated to explore the effects of urban form on energy demand in buildings and communities. Although urban form is not the only driver of energy demand in the built environment, there is evidence suggesting the significance of its impact associated with urban heat island effect, changes in wind pattern, building thermal comfort, and energy conservation [16].

Owens [15] points out to the difficulty of finding a relationship between urban form and buildings' energy demand. Silva et al. [16] back that up by reasoning the manifold of relevant urban spatial attributes that impact energy demand in communities. Ewing and Cervero [28] emphasize the importance of a comprehensive study of the combined effect of all relevant urban attributes in order to 
understand the relationship between urban form and energy demand in communities. They argue that the isolated effect of each individual attribute of urban form has a relatively small effect on the community's overall energy demand. A multidimensional approach for studying this relationship is associated with the complexity of considering all energy relevant attributes of urban form. Nonetheless, according to Silva et al. [16] research on the relationship between urban form and energy demand in communities has been increasingly attracting attention during the last decades.

Owens [15] asserts that the main impact of urban form is on the energy required for space heating, cooling, and lighting in buildings and communities. She claims that buildings and communities should be designed and planned in a way that, as the first step, their required energy is minimized and secondly they take maximum advantage of site's free energy (like sunlight for daylighting and heating and wind for natural ventilation and cooling) to compensate for those needs. By integrating these two steps in the early phases of design and planning, the need for purchasing energy for active energy systems in buildings and communities will be minimized. In the case of community microgrids, the energy generated onsite by renewables or other clean energy resources will be used for the operation of active energy systems like those needed for heating, air conditioning, and ventilation (HVAC). If the energy needs of a microgrid-connected community go beyond the supply of onsite generated energy, the microgrid will connect back to the larger grid for further energy supply. This translates into longer periods of island mode enabling the community to sustain its particular onsite energy generation and less need for reconnecting to the larger grid for further energy supply.

Accordingly, Owens [15] emphasizes siting and orientation as two important urban spatial attributes with implications on energy demand since they can be adjusted to benefit from the site's microclimatic factors and free ambient energy resources. Moreover, a community's orientation, layout, and density can change regional wind patterns impacting the rate of passive cooling and natural ventilation in individual buildings. In addition to density, layout, siting, and orientation, Silva et al. [16] find other urban attributes, including diversity, green areas, passivity, and shading, related to energy demand in buildings.

2.2. A Review of Software Packages for the Modeling, Simulation, and Evaluation of Community Microgrids. Computational methods are typically used to simulate, evaluate, and predict energy performance when designing community microgrid projects. To better understand opportunities and limitations of existing software packages a software survey was conducted and is presented below. Since the relationship between urban form and community energy performance is of interest herein, the presented report excludes analysis on tools merely used for urban planning and those specific to designing the technological details of energy systems. Methods for evaluation started with a literature review, exploration of material available from the software development organizations, and in some cases using the software packages.
2.2.1. Background and Evaluation Criteria. There is existing literature that reviews software packages related to community energy modeling and energy systems modeling. A summary of this work informs the assessment criteria for the software survey conducted in this research.

Allegrini et al. [29] argue the lack of software tools and simulation packages that take into account urban energy systems along with the buildings they serve. In this paper, the authors reviewed different modeling approaches and multidisciplinary tools that address the supply and demand side of an urban energy system and their application to district-level design problems. Authors conducted a descriptive analysis of twenty tools with modeling capabilities in areas relevant to urban energy system design, including some general tools as "TRNSYS" and "Modelica," several specific packages as "CitySim" and "SynCity," and some specialized computational fluid dynamics and geographic information system tools.

Markovic et al. [30] reviewed various practical tools that have been developed to "analyze the energy, economic and environmental performance of energy generation systems, buildings and equipment in a community." These authors categorized related software tools into three main groups according to their aims and achievements: geographical assessment tools, energy assessment tools, and evaluation assessment tools. The geographic assessment tools such as ArcGIS and Raster Cities are used to model geographic features of the built environment, analyze the availability of renewable energy resources, and locate facilities and infrastructures. The energy assessment tools, such as EnergyPLAN and EnergyPlus, take various distributed energy generation scenarios and analyze the energy consumption rates, respectively. The evaluation tools address other aspects of power generation such as life cycle assessment and environmental and socioeconomic analyses. One example of an evaluation tool introduced in this paper is PLACE3S planning for community energy, economic, and environmental sustainability.

Connolly et al. [31] reviewed 37 different computer tools that can be used to analyze the integration of renewable energy into various energy systems under different objectives. Their selection of tools spans from those used for analyzing a single building energy system to those used for large scale, national energy systems. The analysis criteria used in this paper include the energy sector, accounted technologies, time parameters used, and tool availability. Authors conclude that there is no energy tool addressing all issues related to integrating renewable energies. With their paper, they hope to provide necessary information for decision makers in choosing the most appropriate tool for their purposes.

Gil and Duarte [32] identified and compared 12 evaluation tools for sustainable urban development suitable for design and analysis at the neighborhood scale. They studied these tools based on their structure, format, and content, focusing on how the evaluation indicators address dimensions of urban form, accessibility, and the neighborhood's spatiality. Some of the tools reviewed by the authors are CityCAD, DPL, ECOCITY, INDEX, and LEED Neighborhood Development. 


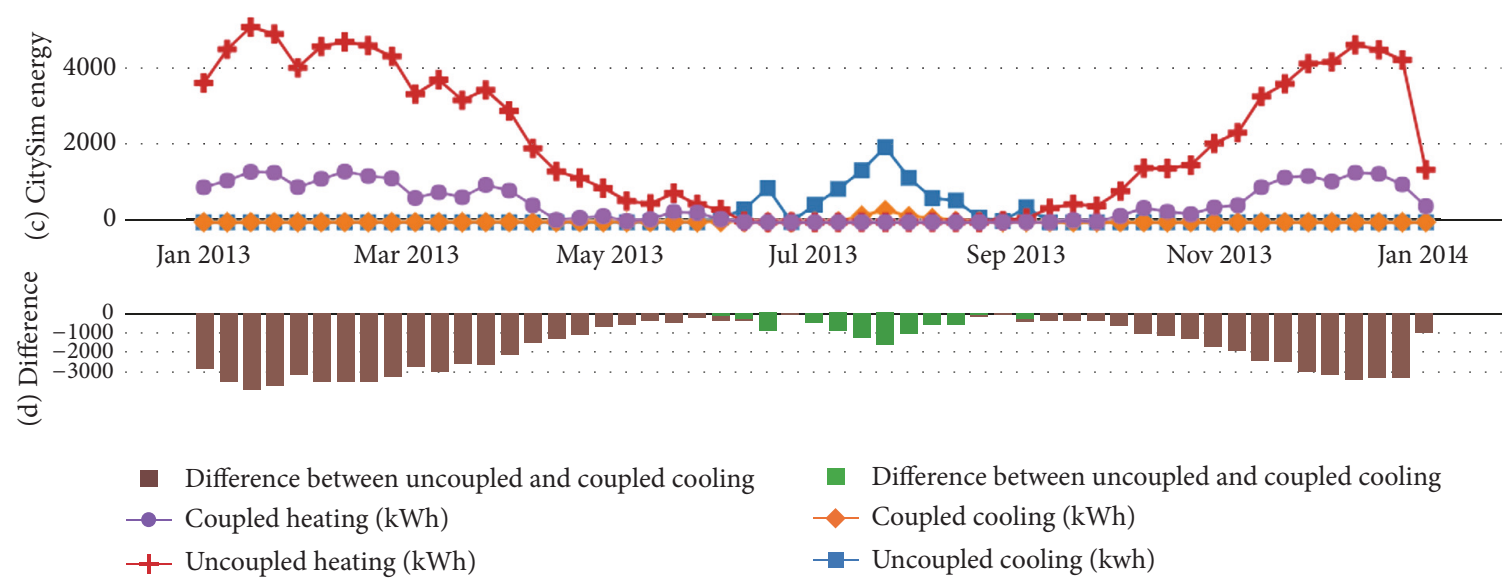

Figure 2: A sample output of CitySim (Source: https://plot.ly/ ClaytonMiller/112.embed).

The missing component in the precedent reviews is the objective of finding software tools that address the interaction between urban superstructure and the performance of its underlying energy infrastructure. The following section offers an assessment of existing software tools relevant for designing and evaluating this interaction. The assessment is done from a perspective of requiring a tool that would address how the urban form of a community impacts the energy performance of its distributed energy system. Consistent with the software survey assessments discussed above, the criteria used for evaluating software tools are as follows:

(i) Functional purpose of the tool which is the tool used for modeling, or simulation/prediction, or evaluation/analysis purposes

(ii) Type of data input

(iii) Output format

(iv) Target users, architects, and urban designers or engineers.

\subsubsection{Urban Superstructure Energy Modeling}

CitySim: Developed by Solar Energy and Buildings Physics Laboratory (LESO-PB), Ecole Polytechnique Federale de Lausanne (EPFL), Lausanne, Switzerland. CitySim is a large scale building energy simulation tool based on simplified thermal models [33]. This is a Java-based graphical user interface (GUI) supporting the decision-making process of sustainable urban planning. The goal of this tool is to simulate and optimize building-related resource flows (energy, water, and waste) and their interrelationships, as well as studying their dependence on the urban climate [34]. The simulation input in CitySim is a manual process based on CityGML geometrical databases including site location, associated climatic data, type and age categories of buildings, 3D forms of buildings, definition of energy supply, and storage systems. CitySim conducts parsing of data in XML format from the GUI to $\mathrm{C}++$ solver for hourly simulation of the resource flows and then streams back the analysis results to the GUI in format of graphs, bars, and tables (Figure 2).

SUNtool: Developed by Solar Energy and Buildings Physics Laboratory (LESO-PB), Ecole Polytechnique Federale de Lausanne (EPFL), Lausanne, Switzerland. SUNtool (Sustainable Urban Neighborhood modeling tool) is the predecessor of CitySim, a Java-based GUI with thermal simulation engines. As a decision-making tool, SUNtool utilizes modeling techniques to predict the performance of various energy generation technologies within the urban context of approximately 50 to 500 buildings. SUNtool is counted as the first of a new generation of simulation tools which supports sustainable master planning [35] based on simulating resource flows as energy, waste, and water. In the interface, the designer models a 3D geometry of the buildings and defines their type of use. Then, the corresponding dataset is specified for location, climate, occupancy schedule, appliances, glazing ratio, construction, systems, and so on. After selecting the simulation setting and running the simulation, the software outputs four classes of model: microclimate (microclimate modeling includes radiation modeling and temperature prediction), thermal, stochastic (stochastic modeling includes occupant presence, window openings, lights and shading devices, electrical and water appliances, and waste), and plant (SUNtool supports a comprehensive plant modeling technique, but it is worth noting that energy resource management, testing and optimizing control strategies, and plant configurations are not one of SUNtool objectives; also, SUNtool does not support energy storage). The accuracy of the conducted simulations enables the designer to choose the best design solution in relation to site-specific urban microclimate as well as to human behavior.

UMI (Urban Modeling Interface): Developed by Sustainable Design Lab at the Massachusetts Institute of Technology (MIT), Cambridge, Massachusetts, USA. UMI is a plugin for Rhinoceros 3D modeling environment, performing environmental analysis for neighborhoods and cities. This analysis is based on operational and embodied energy use (using 


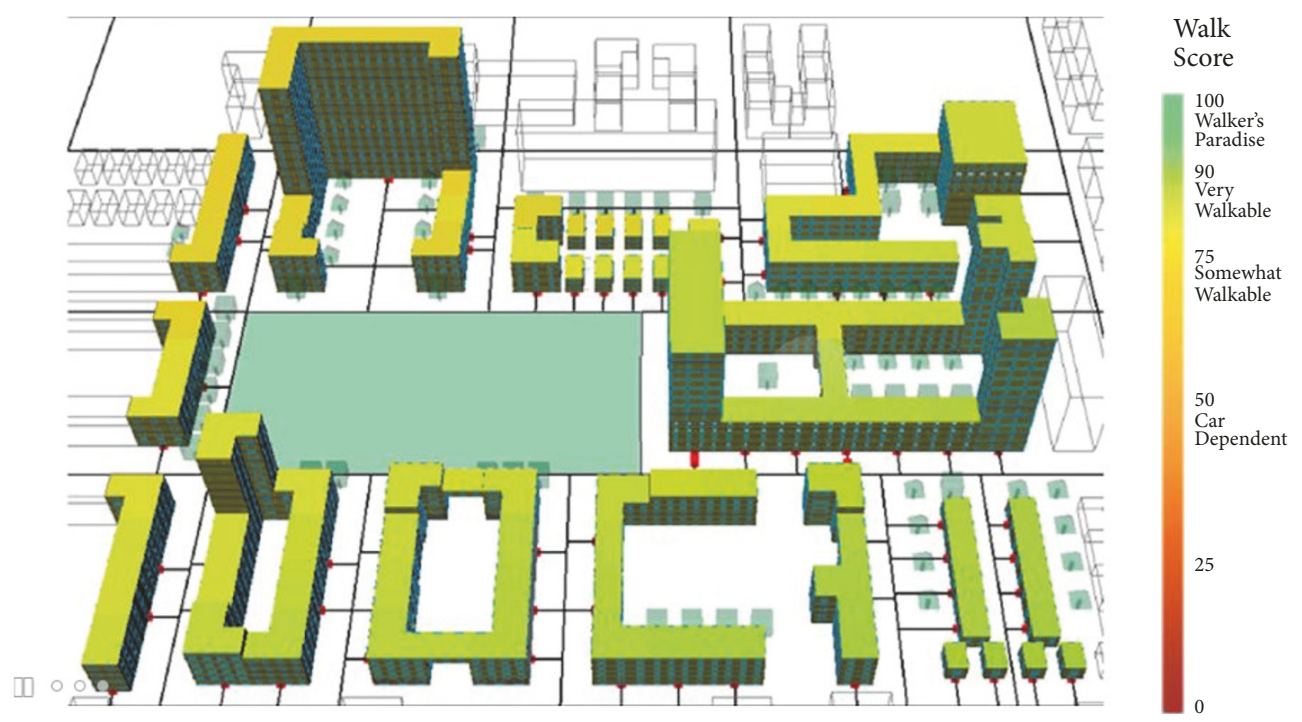

FIGURE 3: UMI output sample (Source: https://architecture.mit.edu/event/modeling-urban-sustainability-energy-daylight-and-walkability).

EnergyPlus' thermal simulation engines), walkability evaluations (using customized Python scripts), and daylighting potential (via Daysim daylighting simulations) [36]. Designers would start modeling their building geometries and massing models in Rhinoceros' CAD environment and then assign their models in UMI. These elements may include building envelopes, trees, shading objects, streets, and other infrastructures. After inputting models in UMI, material specificities may be defined as well as building usage schedules, construction, and amenity types. As the output, UMI runs individual annual simulations for each modeled building mass, calculates the annual daylight availability for each story in each building, and calculates walkability score based on the defined streets, pathways, and selected urban amenities. The outputs are both reflected back into the $3 \mathrm{D}$ model of the Rhinoceros scene and as generated tables and user-friendly graphical reports (Figure 3).

\subsubsection{Energy Infrastructure Energy Modeling}

DER-CAM: Developed by Berkeley Lawrence National Lab, Berkeley, California, USA. DER-CAM is a decision-support tool for decentralized energy systems. The primary objective of DER-CAM is to run technoeconomic evaluation on defined onsite energy generation technologies, CHP, or microgrids and optimize (the output objective of DER-CAM is minimizing the operating costs of onsite energy generations, CHP, or microgrids) the DER selection and operation through linear programming techniques. The inputs for this tool include customers' end use load profiles, customers' default electricity tariffs and natural gas price, initial investment capital, operating and maintenance cost and specificities, basic physical characteristics of alternative generating, and heat recovery and cooling technologies, as well as carbon emission constraints and sensitivity parameters [37]. DERCAM outputs the optimal distributed generation and CHP technologies to be installed with their appropriate level of capacity, the optimal distribution strategy, and the total cost of producing electric and thermal energy [37]. Outputs are in the format of tables and graphs (Figure 4).

HOMER: Developed by National Renewable Energy Laboratory (NREL). HOMER is developed with the purpose of evaluating grid-connected and off-grid energy systems from an economic and engineering point of view. Simulating the performance of any particular energy system configuration is HOMER's main capability. However, the software is also adequately able to run economic optimization and sensitivity/uncertainty analysis on defined systems. It is worth noting that optimization is done on variables that the designer has control over. Sensitivity analysis is on variables that are subject to uncertainty or change which are out of designer's control such as wind speed and fuel price [38]. The input data of HOMER include customer's load profiles for electric and thermal energy, any resources and fuel used by the system to generate electric and thermal power, energy system components (generation, distribution, storage, etc.), electric and thermal load curve with up to 1-minute resolution, technical efficiencies, operation and maintenance costs, emission constraints, and sensitivity parameters [38]. HOMER outputs the evaluation and analysis results in the format of graphs and detailed data reports.

LEAP: Developed by Stockholm Environment Institute (SEI). LEAP (Long Range Energy Alternatives Planning) is an integrated scenario-based energy modeling tool which primarily operates as an accounting system with a capacity for simulation and econometric modeling [39]. In these scenarios, a group of input data are set including the electrical and thermal load profiles, the availability of energy resources, operation and maintenance costs, technical efficiencies, and emission constraints. Some assumptions are also being specified on the population growth rate of the energy system, its futuristic economic development, and the interest rate of the 


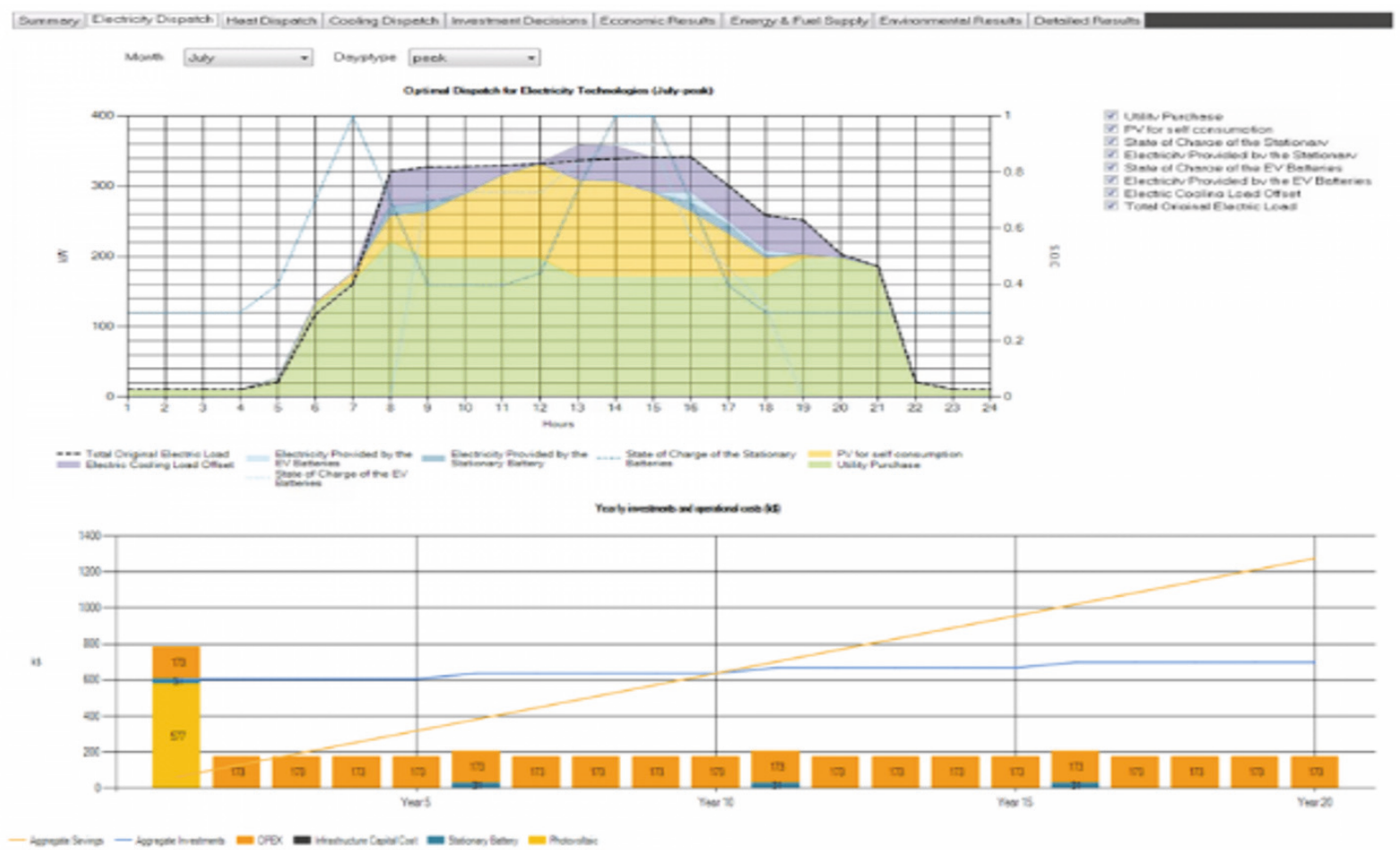

FIGURE 4: DER-CAM output sample (Source: https://building-microgrid.lbl.gov/projects/der-cam).

energy system. Based on the set assumptions, LEAP evaluates the energy scenario by conducting a physical computing of natural and environmental resources, sensitivity parametric analysis, and integrated energy/environment analysis. The outcome of these analysis is in form of detailed reports and graphs of the energy scenario [40].

EAM (Economic Evaluation of Microgrids). EAM is used to evaluate microgrids' economic viability. EAM's objective is to optimize the sizing of any microgrid scenario in relation to the equipment unit selection and its corresponding power capacity. The input measures include a 24-hour energy profile of the energy system, selection of microgrid equipment components, and their initial costs, as well as utility prices [41]. The analysis output of this software package includes tables, graphs, and charts.

MARKAL/TIMES (Market Allocation Model and the Integrated MARKAL/EFOM System): Developed by International Energy Agency's Energy Technology Systems Analysis Program. TIMES and MARKAL share the basic modeling paradigms by being technology explicit and representing equilibrium models of energy markers. However, the development history of MARKAL/TIMES indicates that TIMES is the developed version of MARKAL featuring new analytical capabilities. MARKAL/TIMES is an energy, environmental, and economic evaluation tool that analyzes user-defined energyenvironment systems at the global, national, state/province, or community level and over a long a period of time (up to 100 years) as a representation of their evolution [31]. General input data include demand curve, renewable energy resources, energy station capacities, cost and number of different regulation strategies emphasizing import/export, and excess electricity production. Policy scenarios can also be included as input data with measures on cutting emissions, promoting energy efficiency, improving energy security, and reducing new technical costs. The input data should represent the evolution of the system over time in any user-defined time resolution such as seasonal, monthly, weekly, and hourly time measures [41]. With this data, MARKAL/TIMES models the entire energy system in the defined policy scenarios and depicts all possible flows of energy in different phases of extraction/generation, transformation, distribution, and consumption in the format of tables, charts, and graphs. The software then finds the "best" energy system technical mix at each period of time that meets the demand at minimum cost within the limits of all imposed policies and physical constraints [41].

RETScreen Clean Energy Project Analysis Software: Natural Resources of Canada. RETScreen is a decision-support tool which performs comparisons between any given different energy system scenarios. The software requires three sets of data to input: (1) project specific general information including site location and energy system specificities (generation types, demand load, and technical features), (2) project economics such as initial, annual, and periodic costs, and (3) user specific financial parameters including greenhouse gas emission reduction credits, incentives, inflation, discount rate, and taxes [42]. After inputting the projects' specificities, the software runs comprehensive identification, assessment, and optimization of the technical and economic viability of 


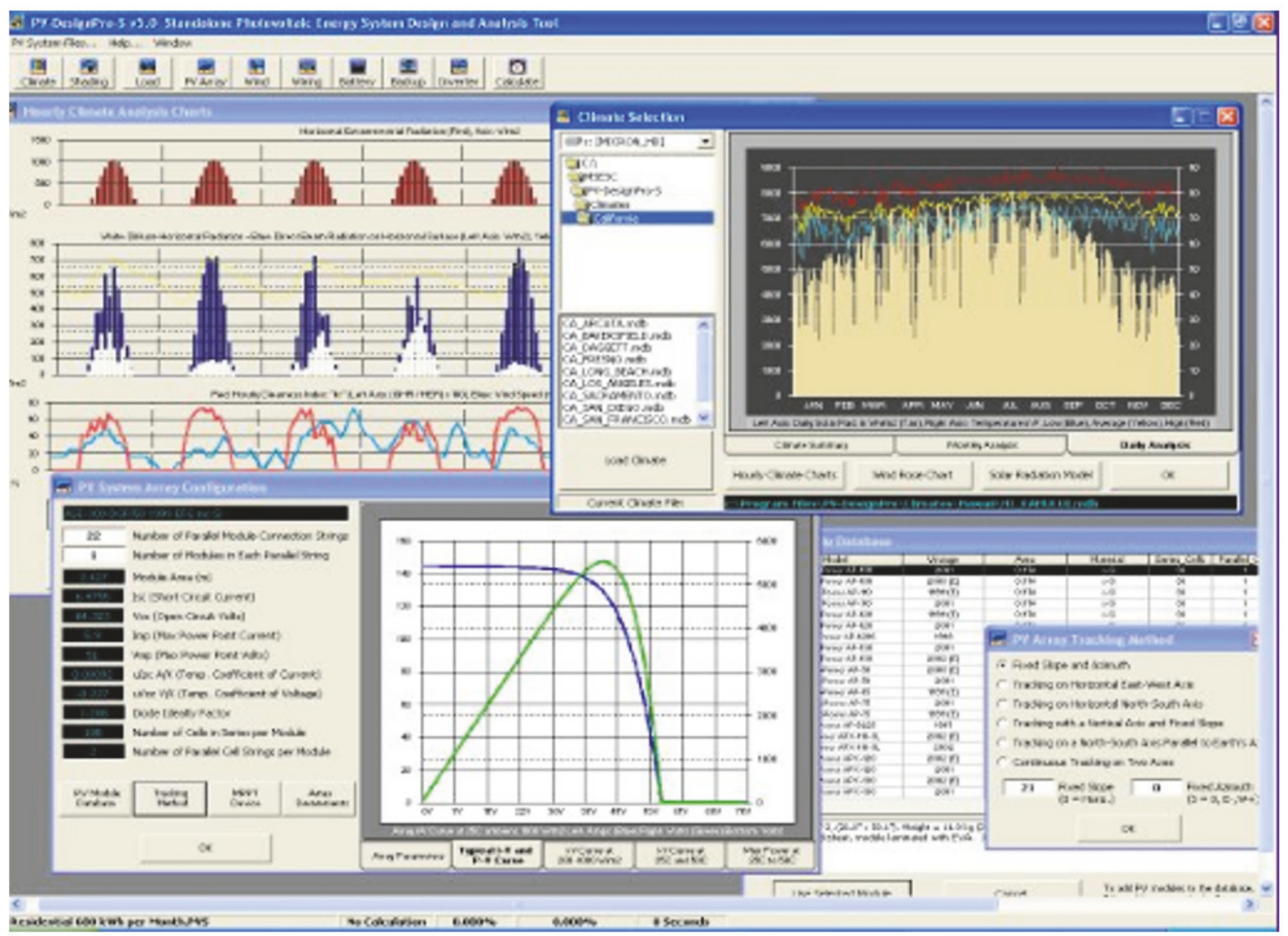

FIGURE 5: PV-Design Pro output sample (Source: http://www.mauisolarsoftware.com/).

the proposed scenarios, as well as measuring and verifying the resultant greenhouse gas emission reductions [29]. The output is in form of summary worksheets, and statistical data visualizations such as graphs, charts, and tables.

PV-Design Pro: Maui Solar Energy Software Corporation, Haiku, Hawaii. PV-Design Pro is designed to simulate photovoltaic energy system operation with the purpose of evaluating PV designs more effectively and maximizing their performance. This software requires modeling and laying out the energy system's components and configuration by inputting climatic loads for different time resolutions, specifying number of panels and electrical characteristics of the PV arrays, designing the wiring configuration, and setting the battery and inverter qualities [43]. The software evaluates the modeled solar energy system, by computing the monthly percentage of electricity generated by the PVs, monthly battery states-of-charge, annual energy costs analysis, life cycle financial analysis, and hourly analysis of the system loads and battery state-of-charge. The outputs are in form of detailed reports, charts, and graphs (Figure 5).

$P V * S O L$ : Berlin, Germany. $\mathrm{PV} * \mathrm{SOL}$ is a dynamic PV simulation program with $3 \mathrm{D}$ visualization and detailed shading analysis of photovoltaic energy systems [44]. As input data, $\mathrm{PV} * \mathrm{SOL}$ enables simple 3D design and modeling of buildings
(Figure 6) along with their featured arrays of photovoltaic panels, modeling and circuit design of the grid along with its mechanical components, dimensioning AC and DC wirings, and implementing the costs of PV components. By adding climatic data of the site location and defining the system features, $\mathrm{PV} * \mathrm{SOL}$ is enabled to simulate the energy produced by the photovoltaic panels and optimize the energy system's configuration while performing economic analysis [44]. The output of this analysis includes 3D visualization (Figure 7), detailed reports, graphs, and charts.

\section{Discussion}

This software survey indicates two distinct categories of modeling, simulation, and evaluation tools that respond to a multidimensional and building-integrated definition of community microgrids (Table 1): (1) energy infrastructure modeling; (2) urban superstructure energy modeling. Software tools from the first category are mostly concentrated on evaluating and optimizing the cost, selection, and operation of individual components of generation, distribution, and storage technologies of distributed energy systems as microgrids. The second category of software tools is used to model, predict, and simulate operational energy use for groups of buildings at the urban level. 


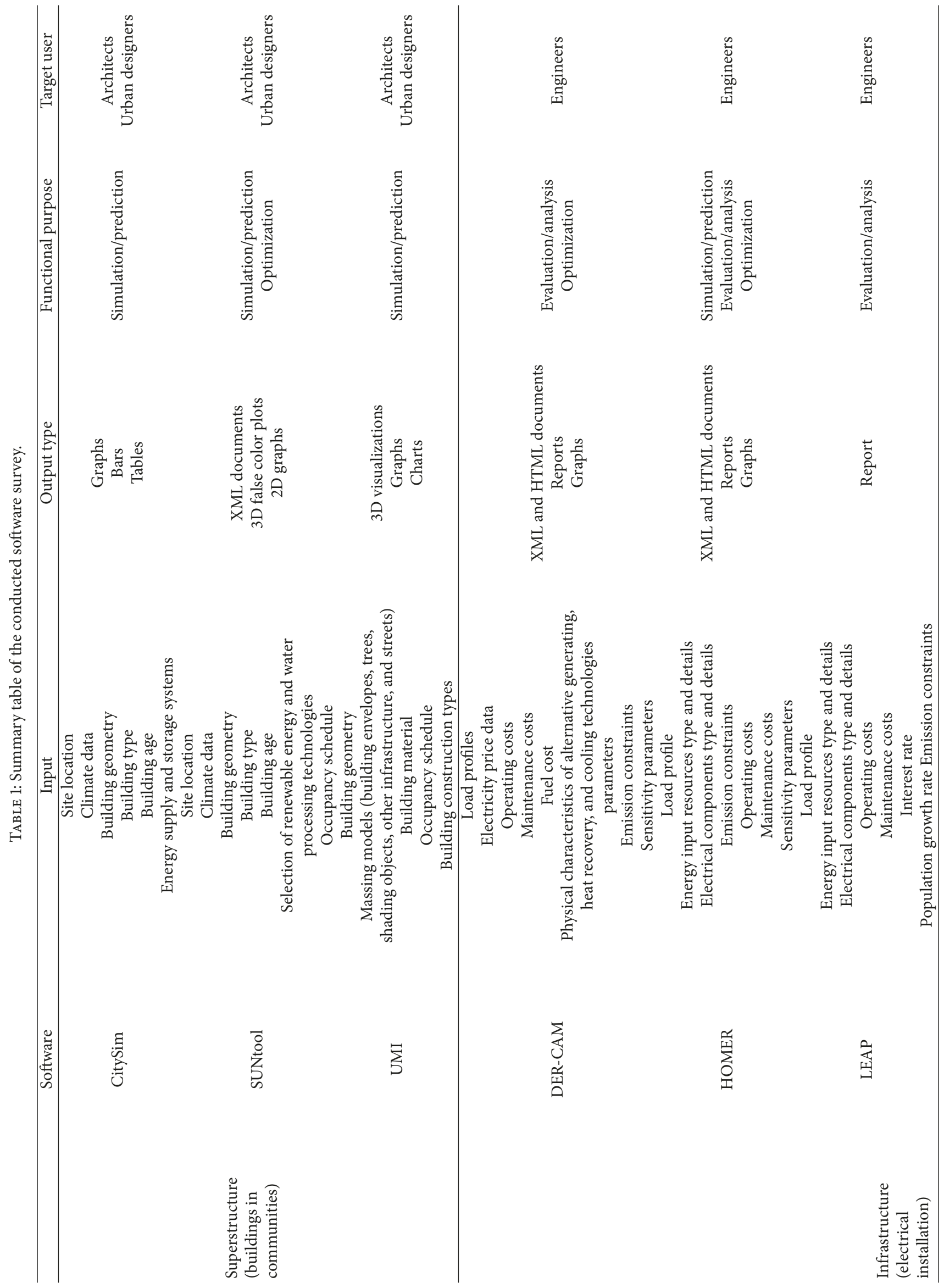




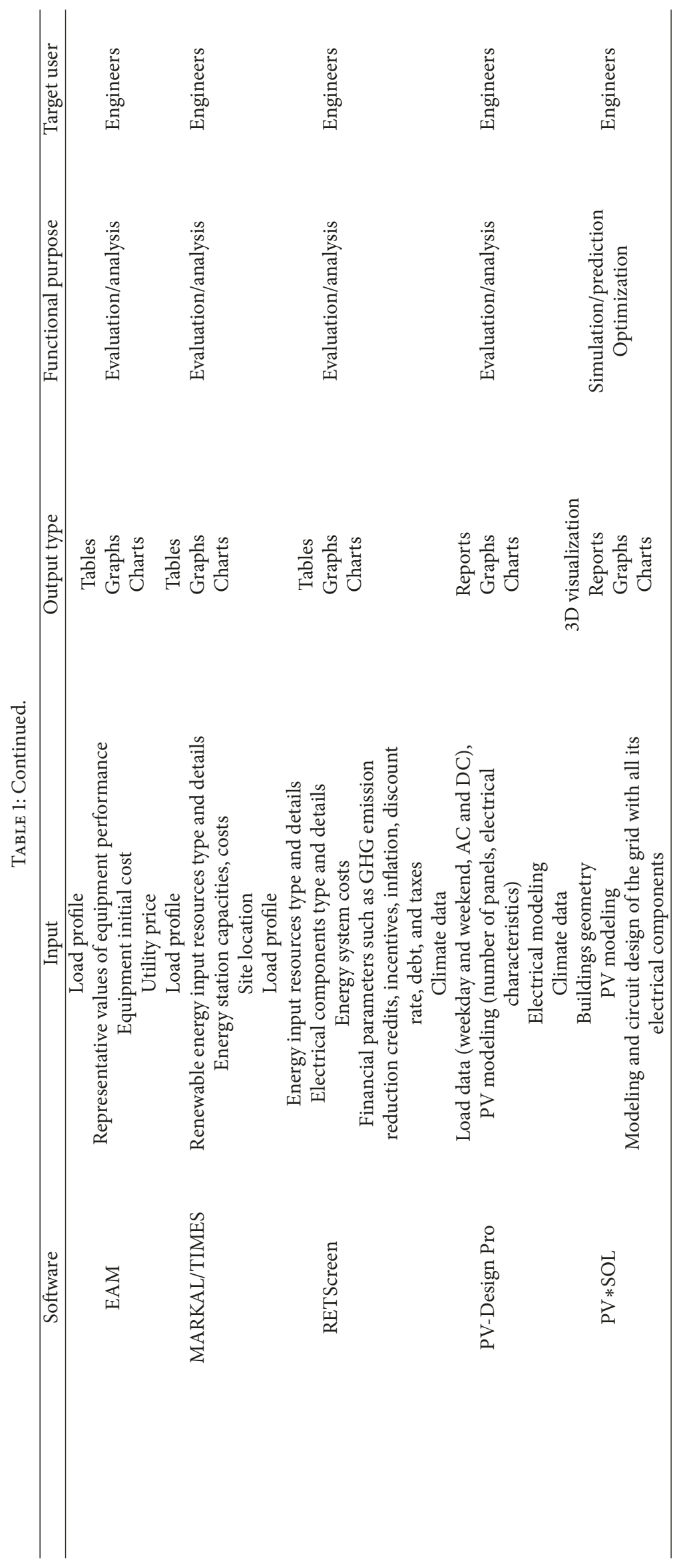




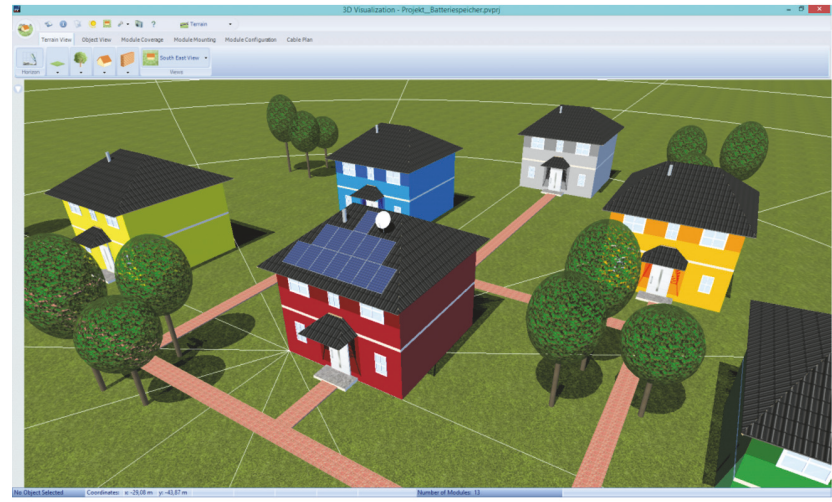

FIGURE 6: PV*SOL 3D building modeling sample (source: http:// solarprofessional.com/articles/design-installation/performance-modeling-tools-overview/page/0/2).

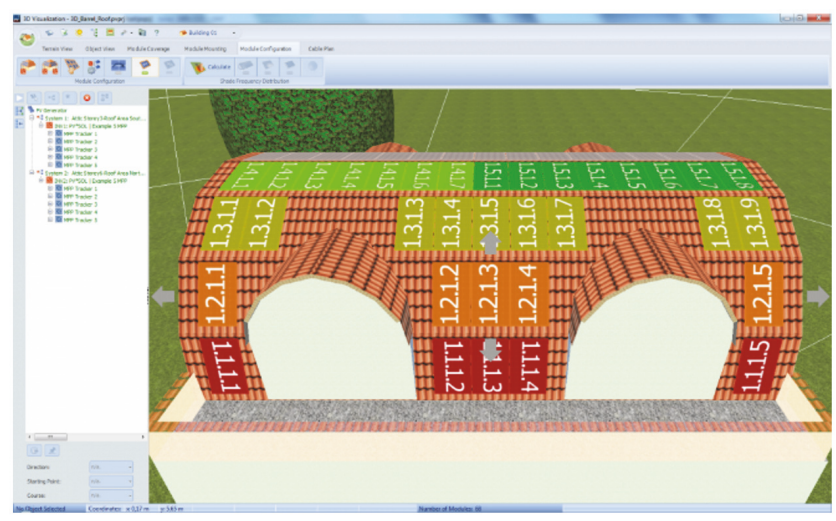

FigURE 7: PV $*$ SOL 3D visualization of PV energy evaluation (source: http://www.valentin-software.com/en/products/photovoltaics/57/pvsolpremium).

Based on this review there is a lack of software tools and simulation packages that simultaneously address the necessary interaction between building in communities and energy performance. Software tools like SUNtool use the 3D modeling of buildings to predict and simulate the performance of photovoltaic energy generators. The limitation of this tool is that it predicts the performance of only one component of an energy system, the energy input. Analysis on how urban form impacts energy output including energy consumption and energy loss is not taken into account. CitySim on the other hand considers energy output in addition to energy supply but does not consider energy loss. The analysis of CitySim is on weather data and not on how the mix of urban form attributes impacts the flow of energy. Since these tools are designed for architects and urban planners, the input of the software is building geometries.

The other category of software studies, the energy system modeling tools, is precisely focused on the operation of the entire energy infrastructure, that is, the mix of all electrical components. Tools as HOMER and DER-CAM optimize the mix of different electrical components in the infrastructure based on overall cost of operation and maintenance.
The optimization feature of HOMER and DER-CAM helps the user explore alternative solutions for the infrastructure design. This is while, as seen in Table 1, the rest of the software packages exclusively run a performance analysis of the inputted infrastructure design and ultimately output an evaluation report. While the main users of these tools are engineers, unlike the first software category introduced, the input for the system is not building geometries but is load energy consumption profiles. Thus, the impact of urban form in predicting the performance of the energy system is completely ignored in such tools.

The software survey studied in this section shows that although some urban superstructure energy modeling tools attempt to address the impact on energy performance, a comprehensive comparison of energy input to energy output has been neglected. Also, the impact of superstructure in the software is limited to individual building geometry and occupancy schedules and is not on the effect of the entire community's urban form on energy performance. Although the energy infrastructure modeling tools thoroughly evaluate the energy performance of the infrastructure, they clearly do not input the superstructure as an affecting factor in the analysis. The coinciding impact of urban form on energy demand, energy supply, and energy waste is not simultaneously addressed in the software tools evaluated.

Based on the introductory literature review presented in Sections 1 and 2 above, studying the energy performance of community microgrids in isolation from their comprising buildings is insufficient. A specific understanding needs to be gained on how the features of urban form can simultaneously maximize onsite renewable energy generation (specifically photovoltaic energy due to its popularity in existing settings) in community microgrids and minimize the community's energy demand. Such a multimodal study of community microgrids requires a new generation of computational modeling, simulation, and evaluation tools.

\section{Conclusion and Next Steps}

The reviewed software survey identifies a gap in existing software tools that simultaneously address the necessary interaction between the superstructure and infrastructure of community microgrids, given the importance of its impact. This software investigation serves as the basis for developing an experimental software prototype that bridges this gap by predicting the energy performance of any given community microgrid design scenario by virtue of its urban spatial configuration. The goal is to use machine learning as a means for knowledge discovery on how urban form and energy performance in communities are related and use the predictive model as the back end of the software prototype. This software is oriented towards assisting architects and urban planners in designing high energy performance microgrid-connected communities by enabling them to view the impact of their designs on the microgrid's energy performance in real-time. The expression "real-time" is used rather deliberately to imply the benefit of adopting machine learning as a method for the simultaneous energy performance simulation and prediction of any given community microgrid spatial design scenario. 
The relationship between community's urban form, net energy consumption, and onsite net PV energy production is assessed in this research. San Diego is selected as a casestudy due to the availability of energy performance data. Using GIS maps, different urban typologies in San Diego are identified and their rules of urban form are extracted. The identified typologies and urban form configurations are 3D-modeled in Rhinoceros ${ }^{\circledR}$ along with the placement of existing PV panels. Using appropriate plugins, the energy performance of these communities is simulated, and the resulting values are compared and calibrated with actual energy data. Based on the extracted rules of different urban typologies, a generation-evaluation algorithm is used to generate multiple configurations of urban form and surfaces for PV energy production. For each configuration, the urban form is quantified by measuring its energy relevant spatial attributes, and the community's net monthly PV energy production and energy consumption are estimated via the calibrated simulator. A machine learning algorithm is trained on the aggregated synthetic numerical data of urban form and energy performance to find its underlying relational pattern. The learned model is used as the back end of the software prototype which inputs $3 \mathrm{D}$ spatial design scenarios of communities and in real-time outputs monthly estimations of net PV energy production and energy consumption as a solar community microgrid.

Although the proof-of-concept prototype is limited to San Diego, it will inform the development of a generalized software package. Pairing the dynamic representation of spatial data with energy performance, this tool enables designers to decide on the urban form of solar microgrid-connected communities that yields a higher energy performance.

\section{Conflicts of Interest}

The authors declare that there are no conflicts of interest regarding the publication of this paper.

\section{Acknowledgments}

The authors are grateful for the support of the Penn State Department of Architecture, Stuckeman School, the Stuckeman Center for Design Computing (SCDC), and Hamer Center for Community Design in the development of this work and the work to follow.

\section{References}

[1] S. M. Amin and B. F. Wollenberg, "Toward a smart grid," IEEE Power \& Energy Magazine, vol. 3, no. 5, pp. 34-41, 2005.

[2] H. Farhangi, “The path of the smart grid," IEEE Power \& Energy Magazine, vol. 8, no. 1, pp. 18-28, 2010.

[3] S. J. Kang, J. Park, K. Oh, and H. Park, "Scheduling-based real time energy flow control strategy for buildingenergy management system," Energy and Building, pp. 239-248, 2014.

[4] C. Villareal, D. Erickson, and M. Zafar, Microgrids: A Regulatory Perspective, CPUC Policy and Planning Division, California, Calif, USA, 2014.
[5] T. K. Paglia, Energy Improvement Districts and Local Energy Production [M.S. thesis], Cornell University, New York, NY, USA, 2011.

[6] M. Rahimian, L. D. Iulo, and D. C. Llach, "The case for a collaborative energy sharing network for small scale community microgrids," in Architecture and Resilience on the Human Scale, pp. 215-222, The University of Sheffield, England, UK, 2015.

[7] G. R. Sherman, Sharing Local Energy Infrastructure - Organizational Models for Implementing Microgrids and District Energy Systems in Urban Commercial Districts, Massachusetts Institute of Technology, Massachusetts, Mass, USA, 2007.

[8] D. T. Ton and M. A. Smith, “The U.S. Department of Energy's Microgrid Initiative," The Electricity Journal, vol. 25, no. 8, pp. 84-94, 2012.

[9] Q. Fu, A. Nasiri, A. Solanki, A. Bani-Ahmed, L. Weber, and V. Bhavaraju, "Microgrids: architectures, controls, protection, and demonstration," Electric Power Components and Systems, vol. 43, no. 12, pp. 1453-1465, 2015.

[10] N. Lidula and A. Rajapakse, "Microgrids research: a review of experimental microgrids and test systems," Renewable and Sustainable Energy Reviews, pp. 186-202, 2011.

[11] L. Mariam, M. Basu, and M. Conlon, "A review of existing microgrid architectures," Journal of Engineering, pp. 1-8, 2013.

[12] Powering a New Generation of Community Energy, from New York State Energy Research and Development Authority, 2015, https://www.nyserda.ny.gov/All-Programs/Programs/NY-Prize.

[13] A. Fernandez and F. Blumsack, Distributing Electric Energy in Rural America Efficiently and Economically: The Micro-grid Option, The Pennsylvania State University, Texas, Tex, USA, 2010.

[14] C. Wouters, "Towards a regulatory framework for microgrids The Singapore experience," Sustainable Cities and Society, vol. 15, pp. 22-32, 2015.

[15] S. Owens, Energy, Planning, and Urban Form, Pion Limited, London, UK, 1986.

[16] M. Silva, V. Oliveira, and V. Leal, "Urban form and energy demand: a review of energy-relevant urban attributes," Journal of Planning Literature, 2017.

[17] P. Steadman, "Energy and patterns of land use," Journal of Architectural Education, vol. 30, no. 3, pp. 62-67, 1977.

[18] T. Bourgeois, J. Gerow, F. Litz, and N. Martin, Community Microgrids: Smarter, Cleaner, Greener, Pace Energy and Climate Center, New York, NY, USA, 2013.

[19] R. Compagnon, "Solar and daylight availability in the urban fabric," Energy and Buildings, vol. 36, no. 4, pp. 321-328, 2004.

[20] G. Lobaccaro and F. Frontini, "Solar energy in urban environment: how urban densification affects existing buildings," Energy Procedia, pp. 1559-1569, 2014.

[21] C. Seto, S. Dhakal, A. Bigio et al., "Human settlements, infrastructure and spatial planning," in Proceedings of the Climate Change 2014: Mitigation of Climate Change, Contribution of Working Group III to the 5th Assessment Report of the Intergovernmental Panel on Climate Change, O. Edenhofer, R. Pichs-Madruga, Y. Sokona, E. Farahani, S. Kadner et al., Eds., Cambridge University Press, Cambridge, UK, 2014.

[22] L. M. A. Bettencourt, J. Lobo, D. Helbing, C. Kühnert, and G. B. West, "Growth, innovation, scaling, and the pace of life in cities," Proceedings of the National Acadamy of Sciences of the United States of America, vol. 104, no. 17, pp. 7301-7306, 2007.

[23] S. Bastianoni, F. M. Pulselli, and E. Tiezzi, "The problem of assigning responsibility for greenhouse gas emissions," Ecological Economics, vol. 49, no. 3, pp. 253-257, 2004. 
[24] D. Dodman, "Blaming cities for climate change? An analysis of urban greenhouse gas emissions inventories," Environment and Urbanization, vol. 21, no. 1, pp. 185-201, 2009.

[25] A. Grubler, X. Bai, T. Buettner, S. Dhakal, D. Fisk, T. Ichinose et al., "Urban Energy Systems. In Global Energy Assessment," in Toward a Sustainable Future, Chapter 18, pp. 1307-1400, Cambridge University Press, Cambridge, UK, 2012.

[26] S. Jebaraj and S. Iniyan, "A review of energy models," Renewable \& Sustainable Energy Reviews, vol. 10, no. 4, pp. 281-311, 2006.

[27] P. W. G. Newman and J. R. Kenworthy, "Gasoline consumption and cities: a comparison of U.S. cities with a global survey," Journal of the American Planning Association, vol. 55, no. 1, pp. 24-37, 1989.

[28] R. Ewing and R. Cervero, "Travel and the built environment: a meta-analysis," Journal of the American Planning Association, vol. 76, no. 3, pp. 265-294, 2010.

[29] J. Allegrini, K. Orehounig, G. Mavromatidis, F. Ruesch, V. Dorer, and R. Evins, "A review of modelling approaches and tools for the simulation of district-scale energy systems," Renewable \& Sustainable Energy Reviews, vol. 52, pp. 1391-1404, 2015.

[30] D. Markovic, D. Cvetkovic, and B. Masic, "Survey of software tools for energy efficiency in a community," Renewable \& Sustainable Energy Reviews, vol. 15, no. 9, pp. 4897-4903, 2011.

[31] D. Connolly, H. Lund, B. V. Mathiesen, and M. Leahy, "A review of computer tools for analysing the integration of renewable energy into various energy systems," Applied Energy, vol. 87, no. 4, pp. 1059-1082, 2010.

[32] J. Gil and J. Duarte, "A review of urban design sustainability evaluation tools," in Proceedings of the 10th International Conference on Design and Decision Support Systems in Architecture and Urban Planning, Eindhoven University of Technology, Eindhoven, Netherlands, 2010.

[33] E. Walter and J. Kämpf, "A verification of CitySim results using the BESTEST and monitored consumption values," in Proceedings of the 2nd Building Simulation Applications conference, pp. 215-222, Bozen-Bolzano University Press, Bozen-Bolzano, Italy, 2015.

[34] D. Robinson, F. Haldi, J. Kämpf et al., "CitySim: comprehensive micro-simulation of resource flows for sustainable urban planning," in Proceedings of the 11th International IBPSA Conference, pp. 1083-1090, Building Simulation, Glasgow, Scotland, UK, 2009.

[35] D. Robinson, N. Campbell, W. Gaiser et al., "SUNtool - A new modelling paradigm for simulating and optimising urban sustainability," Solar Energy, vol. 81, no. 9, pp. 1196-1211, 2007.

[36] C. F. Reinhart, T. Dogan, J. A. Jakubiec, T. Rakha, and A. Sang, "UMI - An urban simulation environment for building energy use, daylighting and walkability," in Proceedings of the 13th Conference of the International Building Performance Simulation Association, BS 2013, pp. 476-483, August 2013.

[37] Lawrence Berkeley National Laboratory (LBNL), DER-CAM User Manual, Berkeley, California, Calif, USA, LBNL, 2015.

[38] T. Lambert, P. Gilman, and P. Lilienthal, "Micropower system modeling with HOMER," Integration of Alternative Sources of Energy, vol. 1, no. 15, pp. 379-418, 2006.

[39] LEAP - long range energy alternatives planning, 2017, http://www .seib.org/leap/.

[40] Commend - community for energy, environment and development, 2017, http://www.energycommunity.org/.

[41] G. Mendes, C. Ioakimidis, and P. Ferrão, "On the planning and analysis of integrated community energy systems: a review and survey of available tools," Renewable and Sustainable Energy Reviews, vol. 15, no. 9, pp. 4836-4854, 2011.

[42] G. Leng, "RETScreen ${ }^{\mathrm{TM}}$ International: a decision support and capacity building tool for assessing potential renewable energy projects," Industry and Environment, pp. 22-23, 2000.

[43] Maui Solar Energy Software Corporation, 2017, http://www .mauisolarsoftware.com/.

[44] “PV*SOL Premium, 2017," http://www.valentin-software.com/ en/products/photovoltaics/57/pvsol-premium. 


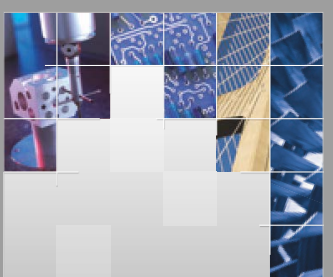

\section{Enfincering}
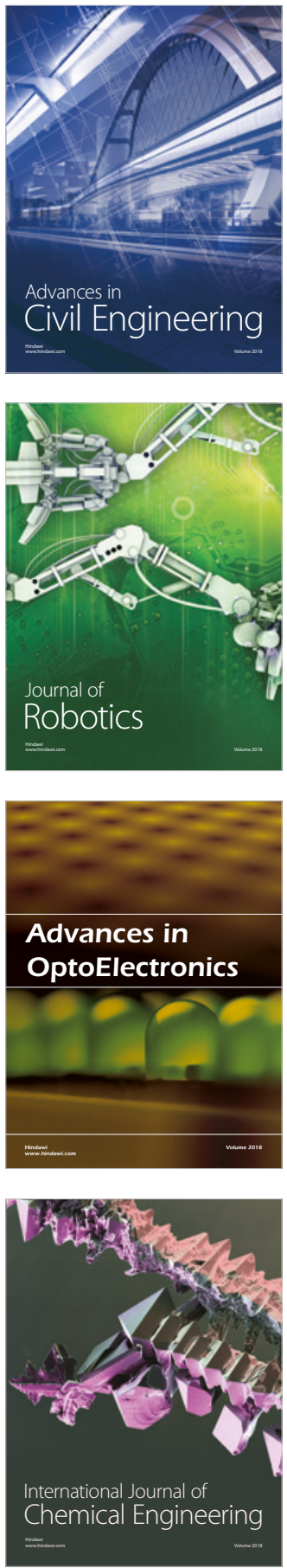

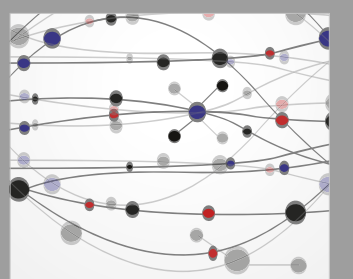

\section{Rotating \\ Machinery}

The Scientific World Journal

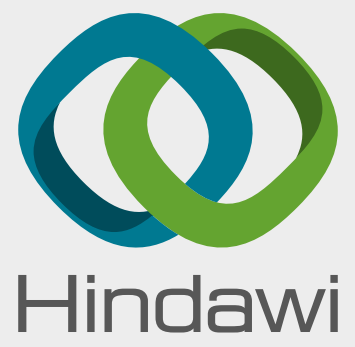

Submit your manuscripts at

www.hindawi.com
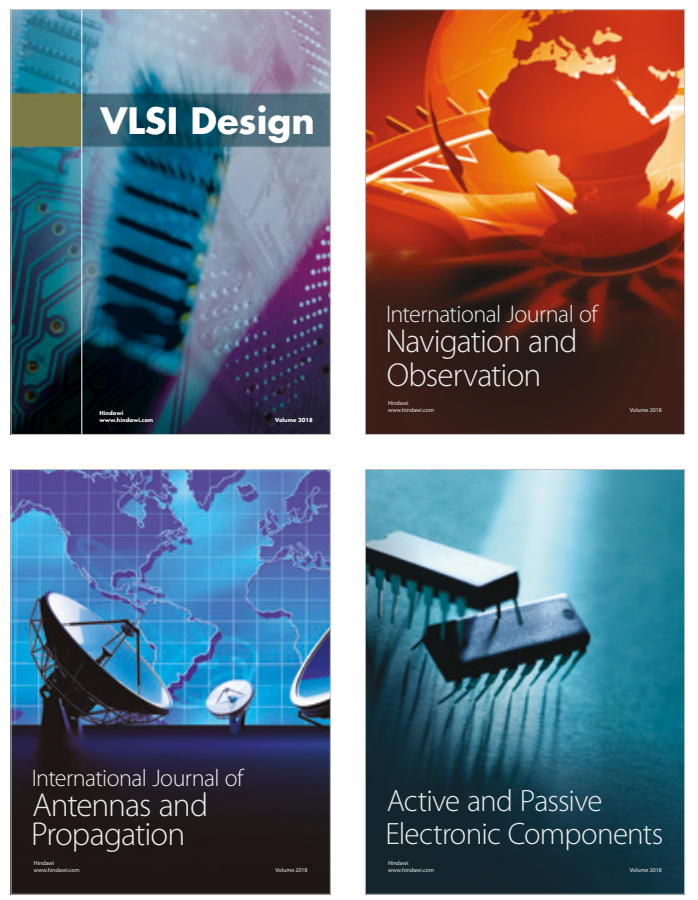
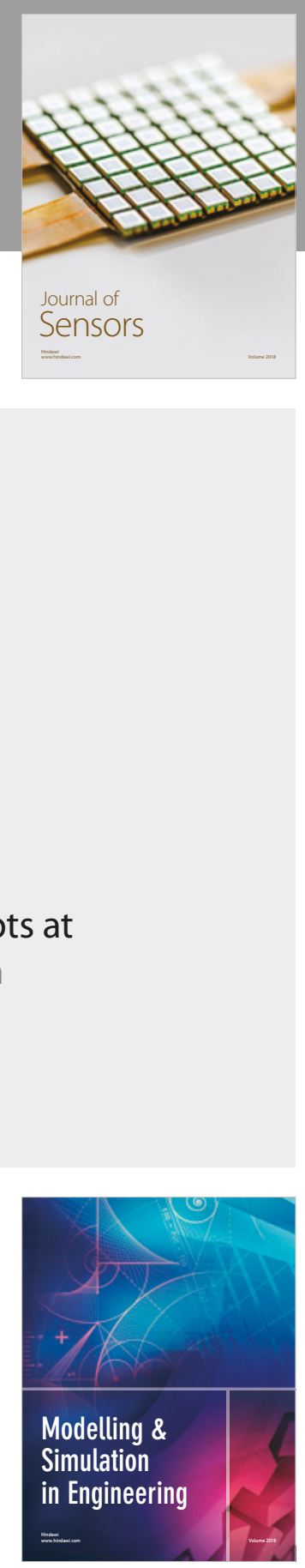

\section{Advances \\ Multimedia}
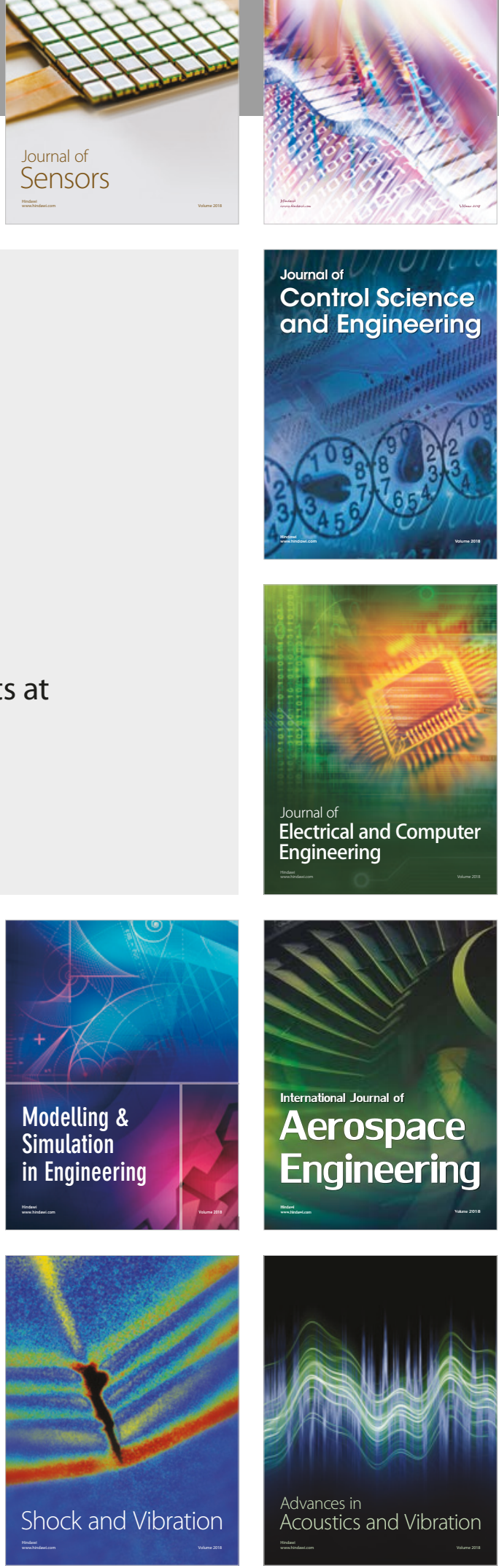